\title{
Unexpected photochemistry and charge-transfer complexes of $\left[\mathrm{CB}_{11} \mathrm{H}_{12}\right]^{-}$carborane $\dagger$
}

\author{
Francesc X. Llabrés i Xamena, ${ }^{a}$ Laura Teruel, ${ }^{a}$ María S. Galletero, ${ }^{b}$ Avelino Corma ${ }^{* a}$ and \\ Hermenegildo García*a
}

Received (in Cambridge, UK) 4th October 2007, Accepted 8th November 2007

First published as an Advance Article on the web 15th November 2007

DOI: $10.1039 / \mathrm{b} 715303 \mathrm{a}$

\begin{abstract}
Although the $\left[\mathrm{CB}_{11} \mathrm{H}_{12}\right]^{-}$carborane does not exhibit an absorption band in UV, its triplet excited state can be generated upon $308 \mathrm{~nm}$ laser excitation; also unexpectedly carborane acts as electron donor forming a charge transfer complex with methylviologen that upon illumination gives rise to viologen radical cation.
\end{abstract}

Since the initial report of Reed and co-workers describing the superacidity of carboranes in their protonic form, there is a renewed interest in this molecule. ${ }^{1-4}$ Carborane $\mathrm{CB}_{11} \mathrm{H}_{12}{ }^{-}$results from the apical isomorphous substitution of a boron in dodecaborane with a carbon atom. ${ }^{5}$ As result of this substitution and the extra carbon electron, a negative charge is introduced in the system and the carborane becomes an anionic species. Carboranes are among the less nucleophilic species due to electron delocalization over the structure. ${ }^{1-4}$ The chemistry and properties of carboranes have recently been reviewed. ${ }^{5-9}$

Carborane does not exhibit any absorption band in the UV/Vis region and, therefore, no photochemistry is expected upon irradiation in this wavelength region. ${ }^{5}$ Also, carborane cannot be oxidized in the potential range commonly available in conventional organic solvents, ${ }^{5}$ although oxidation could occur at higher potentials. In sharp contrast with these two well-known properties of $\mathrm{CB}_{11} \mathrm{H}_{12}{ }^{-}$carborane, herein we report the unexpected observation of photochemical activity of $\mathrm{Cs}\left[\mathrm{CB}_{11} \mathrm{H}_{12}\right]$ and the formation of photoactive charge transfer complexes with a strong electron acceptor.

Optical UV/Vis spectrum of $\mathrm{Cs}\left[\mathrm{CB}_{11} \mathrm{H}_{12}\right]$ in acetonitrile solution shows no peaks in the $200-800 \mathrm{~nm}$ range and only an absorption tail growing to shorter wavelengths is observed (Fig. 1). No transient was observed when $\mathrm{CB}_{11} \mathrm{H}_{12}{ }^{-}$was irradiated using $355 \mathrm{~nm}$ laser. However, upon 308-nm laser excitation of a $\mathrm{N}_{2^{-}}$ purged methanol $0.175 \mathrm{M}$ solution of $\mathrm{Cs}\left[\mathrm{CB}_{11} \mathrm{H}_{12}\right]($ O.D. 0.08) a transient decaying in the microsecond time scale was recorded (Fig. 2). The transient spectrum consists of a broad band expanding from 350 to $650 \mathrm{~nm}$ and peaking at $420 \mathrm{~nm}$. The temporal profile of the signal was coincident in the complete spectral range, this being consistent with the photochemical

\footnotetext{
${ }^{a}$ Instituto de Tecnología Química, Universidad Politécnica de Valencia, Camino de Veras/n, 46022 Valencia, Spain.E-mail:hgarcia@qim.upv.es ${ }^{b}$ Servicio Central de Espectrometria de Masas, Universidad de Valencia, Av. Dr. Moliner 100, Burjassot, Spain

$\uparrow$ Electronic supplementary information (ESI) available: Fig. S1: Dependence of the absorption at $420 \mathrm{~nm}$ of a $\mathrm{Cs}\left[\mathrm{CB}_{11} \mathrm{H}_{12}\right]$ methanolic solution upon laser power. Fig. S2: Quenching of $\mathrm{Cs}\left[\mathrm{CB}_{11} \mathrm{H}_{12}\right]$ with nitromethane. Fig. S3: ESI-MS of a coloured equimolar mixture of $\mathrm{Cs}\left[\mathrm{CB}_{11}\right]$ and $\mathrm{MV}\left(\mathrm{PF}_{6}\right)_{2}$ in acetonitrile. See DOI: $10.1039 / \mathrm{b} 715303 \mathrm{a}$
}

generation of a single transient species (inset of Fig. 2). The signal decay fits well to a first-order kinetics with a half life of $16.2 \mu \mathrm{s}$. The signal from $\mathrm{Cs}\left[\mathrm{CB}_{11} \mathrm{H}_{12}\right]$ generated upon the laser flash is quenched by oxygen (inset of Fig. 2). Taken together, these observations are consistent with the unexpected characterization of carborane triplet excited state.

Since carboranes do not possess absorption bands in the UV, we performed an energy-dependence study to determine whether or

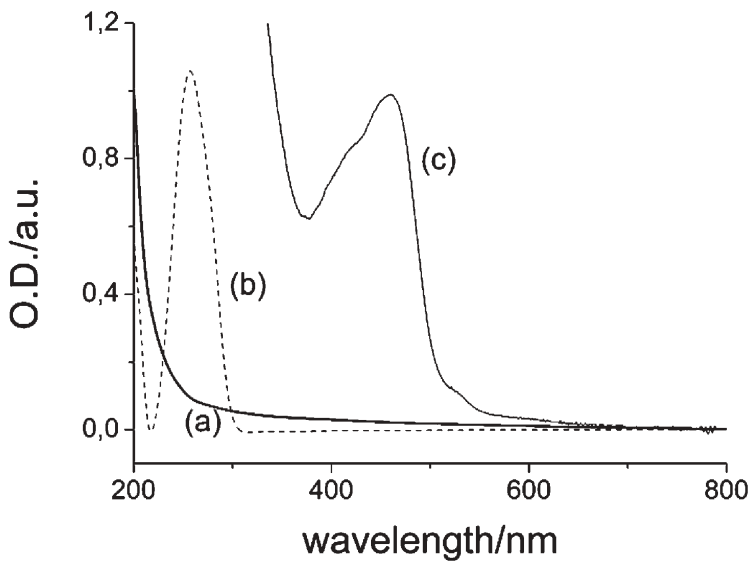

Fig. 1 UV-Vis spectra of acetonitrile solutions of: (a) $\mathrm{Cs}\left[\mathrm{CB}_{11} \mathrm{H}_{12}\right]$ $(0.175 \mathrm{M})$, (b) $\mathrm{MV}\left(\mathrm{PF}_{6}\right)_{2}\left(10^{-4} \mathrm{M}\right)$ and (c) the charge-transfer complex formed upon mixing $0.01 \mathrm{M}$ solutions of $\mathrm{Cs}\left[\mathrm{CB}_{11} \mathrm{H}_{12}\right]$ and $\mathrm{MV}\left(\mathrm{PF}_{6}\right)_{2}$.

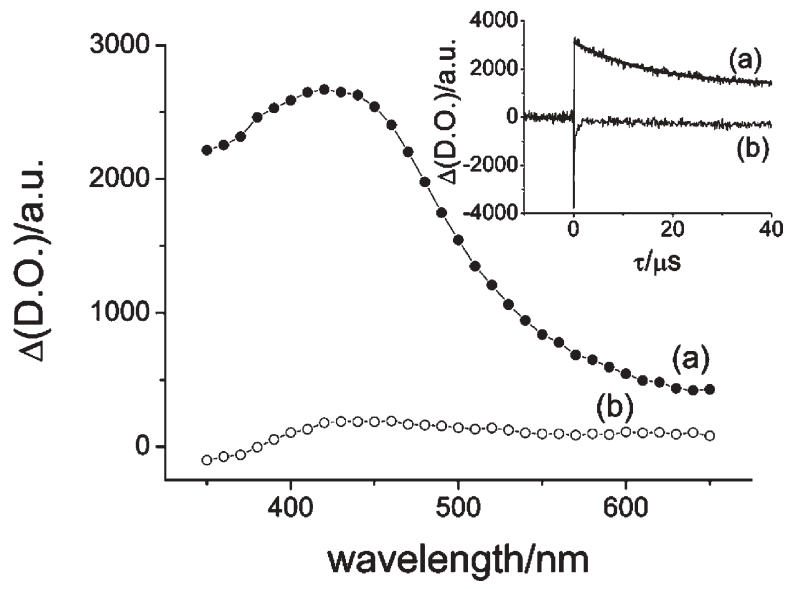

Fig. 2 UV-Vis absorption spectrum recorded $5 \mu$ s after 308-nm laser excitation of a $175 \mathrm{mM}$ methanol solution of $\mathrm{Cs}\left[\mathrm{CB}_{11} \mathrm{H}_{12}\right]$ purged with $\mathrm{N}_{2}$ (a) or with $\mathrm{O}_{2}$ (b). The inset shows the temporal evolution of the signals at $420 \mathrm{~nm}$. 
not excitation under these conditions is a mono- or multi-photonic process. The signal intensity monitored at $420 \mathrm{~nm}$ shows growth with the laser pulse energy (see ESI, $\dagger$ Fig. S1). The relationship between the top $\Delta$ O.D. of the $420 \mathrm{~nm}$ signal after the laser flash and the laser pulse energy in the range studied (from 5 to $24 \mathrm{~mJ}$ ) was not linear and was fitted to a second-order polynomial equation. Thus, some contribution of biphotonic processes takes place. However, according to the empirical equation, at the laser power employed $\left(15 \mathrm{~mJ}\right.$ pulse $\left.{ }^{-1}\right)$, the photogenerated transient arises mainly from monophotonic light absorption.

Electronic excited states are better electron donors and acceptors than ground states. ${ }^{10}$ We observed that the $\mathrm{Cs}\left[\mathrm{CB}_{11} \mathrm{H}_{12}\right]$ triplet excited state is quenched by electron acceptors. The use of $308 \mathrm{~nm}$ excitation limits the nature of the quenchers that can be employed. Nevertheless, we observed that the carborane triplet excited state is quenched by nitromethane, an electron acceptor quencher (see ESI, $\uparrow$ Fig. S2). The quenching rate constant estimated from the plot of the decay rate constant $v s$. the quencher concentration was $1.3 \times 10^{7} \mathrm{~s}^{-1} \mathrm{M}^{-1}$.

In our hands, a solution of $\mathrm{Cs}\left[\mathrm{CB}_{11} \mathrm{H}_{12}\right]$ in acetonitrile does not exhibit any electrochemical peak in cyclic voltammetry in the range from -2 to $+2 \mathrm{~V}$. This agrees with the literature ${ }^{5}$ and seems to imply that $\mathrm{CB}_{11} \mathrm{H}_{12}{ }^{-}$is a poor electron donor, that should not form charge transfer complexes. Unexpectedly, when methylviologen $\left(\mathrm{MV}^{2+}\right)$ hexafluorophosphate is added to a $0.010 \mathrm{M}$ solution of $\mathrm{Cs}\left[\mathrm{CB}_{11} \mathrm{H}_{12}\right]$, the appearance of a new absorption band in the optical spectrum not present in any of the two compounds independently was observed (Fig. 1(c)). $\mathrm{MV}^{2+}$ is a strong electron acceptor that is known to form charge-transfer complexes with electron-donor compounds in solution. ${ }^{11}$ These charge transfer complexes involving $\mathrm{MV}^{2+}$ are characterized by the appearance in the UV-Vis spectrum of a band at longer wavelengths than the independent constituents. ${ }^{11}$ Thus, the changes in the optical spectrum of $\mathrm{Cs}\left[\mathrm{CB}_{11} \mathrm{H}_{12}\right]$ upon addition of $\mathrm{MV}\left(\mathrm{PF}_{6}\right)_{2}$ with the appearance of a $450 \mathrm{~nm}$ band indicates the formation of a chargetransfer complex in spite of the fact that carborane is a poor electron donor. Association of $\mathrm{CB}_{11} \mathrm{H}_{12}{ }^{-}$and $\mathrm{MV}^{2+}$ forming a complex was convincingly confirmed by performing positive electrospray ionization-mass spectrometry (ESI-MS) of the colored solution containing both components (see ESI, $\uparrow$ Fig. S3). Thus, peaks at $\mathrm{m} / \mathrm{z} 1083.2$ and 804.4 compatible with the mass of $\left[\mathrm{Cs}\left(\mathrm{CB}_{11} \mathrm{H}_{12}\right)(\mathrm{MV})_{2}\left(\mathrm{PF}_{6}\right)_{3}\right]^{+}$and $\left[\left(\mathrm{CB}_{11} \mathrm{H}_{12}\right)(\mathrm{MV})_{2}\left(\mathrm{PF}_{6}\right)_{2}\right]^{+}$, respectively, were recorded. The assignment of ESI-MS peaks to these ions is supported by the fragmentation pattern of the respective peaks. Particularly important is that the peak at $\mathrm{m} / \mathrm{z} 1083.2$ gives an ion at $m / z$ 804.4, after losing a fragment of $m / z 272\left(\mathrm{CsPF}_{6}\right)$. Other important peaks correspond to $\mathrm{MV}\left(\mathrm{PF}_{6}\right)^{+}(\mathrm{m} / \mathrm{z} 331.2)$ and $\mathrm{MV}^{2+}(\mathrm{m} / \mathrm{z}$ 93.3). In any case, the fact that peaks with mass considerably larger than those of $\mathrm{Cs}\left(\mathrm{CB}_{11} \mathrm{H}_{12}\right)(\mathrm{m} / \mathrm{z} 275.92)$ or $\mathrm{MV}\left(\mathrm{PF}_{6}\right)_{2}(\mathrm{~m} / \mathrm{z} 476)$ clearly indicates that association is taking place. Concerning the driving force for association between $\mathrm{CB}_{11} \mathrm{H}_{12}{ }^{-}$and $\mathrm{MV}^{2+}$, it is reasonable to propose that the coulombic interaction between anionic $\mathrm{CB}_{11} \mathrm{H}_{12}{ }^{-}$and cationic $\mathrm{MV}^{2+}$ is playing an important role. In this context, observation of a new visible band in optical spectroscopy clearly evidences the orbital overlapping between $\mathrm{CB}_{11} \mathrm{H}_{12}{ }^{-}$and $\mathrm{MV}^{2+}$ typical for charge transfer complexes. ${ }^{11}$

Colored solutions of $\mathrm{Cs}\left[\mathrm{CB}_{11} \mathrm{H}_{12}\right]$ containing $\mathrm{MV}\left(\mathrm{PF}_{6}\right)_{2}$ in the absence of air were submitted to illumination with the output of a
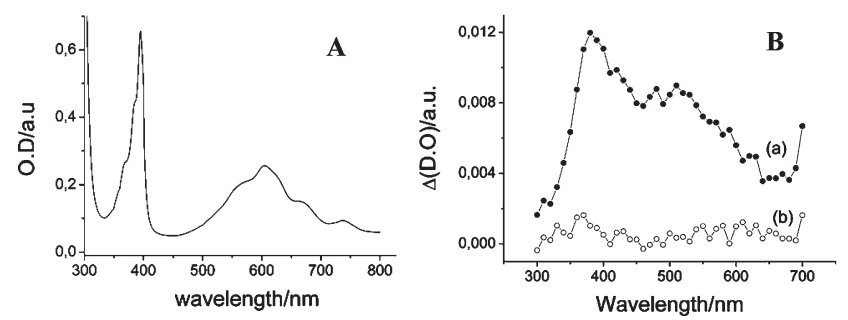

Fig. 3 (A) Optical spectrum recorded upon solar simulator irradiation of a $0.001 \mathrm{M}$ equimolar acetonitrile solution of $\mathrm{Cs}\left[\mathrm{CB}_{11} \mathrm{H}_{12}\right]$ and $\mathrm{MV}^{2+}$; (B) UV-Vis absorption spectrum obtained $10 \mu$ s after $355 \mathrm{~nm}$ laser irradiation of acetonitrile solutions of (a) an equimolar mixture of $\mathrm{Cs}\left[\mathrm{CB}_{11} \mathrm{H}_{12}\right]$ and $\mathrm{MV}\left(\mathrm{PF}_{6}\right)_{2}$; and (b) pure $\mathrm{MV}\left(\mathrm{PF}_{6}\right)_{2}$.

$1000 \mathrm{~W}$ AM1.5 solar simulator. Optical spectroscopy indicates the formation of the $\mathrm{MV}^{\cdot+}$ radical cation (Fig. 3(A)). ${ }^{12}$ Concerning the origin of the electron gained by $\mathrm{MV}^{2+}$ to generate its radical cation, the most reasonable origin is $\mathrm{CB}_{11} \mathrm{H}_{12}{ }^{-}$based on the formation of the charge transfer complex and the observation of ion pairing in ESI-MS. Blank controls under the same conditions in the absence of $\mathrm{CB}_{11} \mathrm{H}_{12}{ }^{-}$adding $\mathrm{CsPF}_{6}$ did not show generation of the $\mathrm{MV}^{\bullet+}$ radical cation, lending support to the proposal of $\mathrm{CB}_{11} \mathrm{H}_{12}{ }^{-}$acting as electron donor. Quantification of the concentration of the $\mathrm{MV}^{{ }^{+}}$radical cation was done based on the absorbance at $590 \mathrm{~nm}\left(\varepsilon_{590}=13900 \mathrm{~cm}^{-1} \mathrm{M}^{-1}\right)$ giving a stationary concentration of $18.5 \mu \mathrm{M}$. This corresponds to a yield of $1.85 \%$ of the $\mathrm{MV}^{2+}$ present in the solution. The fact that $\mathrm{MV}^{2+}$ in its ground state has a reduction potential that is not sufficient to oxidize carborane does not imply that upon photochemical excitation photoinduced electron transfer cannot occur. The higher oxidation potential of $\mathrm{MV}^{2+}$ in its excited state could be high enough to abstract one electron from $\mathrm{CB}_{11} \mathrm{H}_{12}{ }^{-}$. However the fact that photoinduced electron transfer occurs with filtered light corresponding to the absorption of the charge transfer complex indicates that pre-association and charge transfer complex formation is a necessary prerequisite for photoinduced charge separation.

What is remarkable in the spectrum of Fig. 3(A) is the absence of absorption bands attributable to any carborane species. This fact indicates that after electron transfer and generation of carborane radical and $\mathrm{MV}^{*+}$ radical cation, $\mathrm{MV}^{\circ+}$ is persistent while the former is not persistent and evolves towards some products (Scheme 1). To detect product formation from carborane, negative ESI-MS was undertaken. Although the negative ESI-MS of the solution after irradiation is dominated by a huge peak corresponding to $\mathrm{PF}_{6}{ }^{-}$ions, we have been able to detect a peak at $\mathrm{m} / \mathrm{z} 246$ that is compatible with the formation of a carborane dimer through carborane radical coupling after losing an hydrogen atom $(2 \times 123 \mathrm{Da})$. This minor peak was absent in

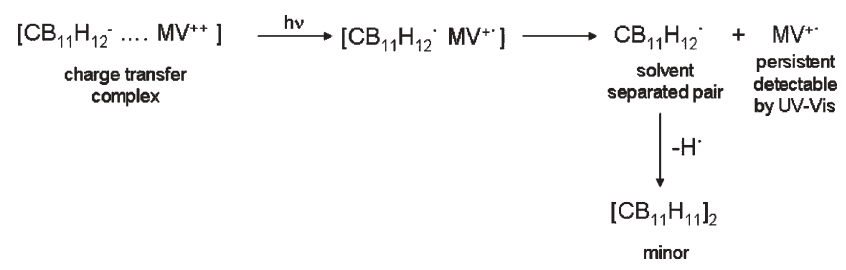

Scheme 1 


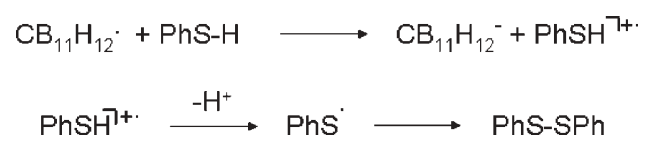

Scheme 2

the unirradiated sample. Formation of carborane dimer even though in small amounts is uncommon. Theoretical calculations for the $\mathrm{CB}_{11} \mathrm{H}_{12}$ radical indicates that the unpaired electron is mainly localized on the boron opposed to the carbon vertex. ${ }^{13}$ Also there are some precedents of the dimerization of decaborane and related derivatives ${ }^{14}$ as well as the permethyl substituted of carborane. $^{5}$

In order to seek evidence for the occurrence of a photoinduced electron transfer upon excitation of the charge-transfer complex, laser flash photolysis of the solution containing $\mathrm{CB}_{11} \mathrm{H}_{12}{ }^{-}$and $\mathrm{MV}^{2+}$ was carried out. It is convenient to remind that previous controls commented on earlier showed that $355 \mathrm{~nm}$ excitation of $\mathrm{CB}_{11} \mathrm{H}_{12}{ }^{-}$does not allow recording any transient. Also another control establishes that $\mathrm{MV}\left(\mathrm{PF}_{6}\right)_{2}$ does not give any transient upon 355-nm excitation. In contrast to the negative results of these controls, $355 \mathrm{~nm}$ excitation of the charge-transfer complex gives rise to the formation of a transient (Fig. 3(B)). The transient spectrum can be interpreted as the overlapping of $\mathrm{MV}^{\cdot+}$ radical cation (sharp absorption at $390 \mathrm{~nm}$ and another much broader and less intense at $600 \mathrm{~nm}$ ) with another species. We propose that this other species corresponds to the carborane radical formed concomitantly with $\mathrm{MV}^{\circ+}$ in the photoinduced electron transfer. These transients are extremely long lived and did not decay in the longest time scale available to our nanosecond laser flash photolysis system $(500 \mu \mathrm{s})$. This persistence is also compatible with the fact that at least $\mathrm{MV}^{\cdot+}$ can be observed by steady-state optical spectroscopy.

As commented earlier, dimer formation from the $\mathrm{CB}_{11} \mathrm{H}_{11}{ }^{\circ}$ radical is most likely an unfavourable process and, thus the peak detected should corresponds to a minor process. In order to seek additional evidence for the occurrence of photoinduced electron transfer we performed the irradiation of the $\mathrm{CB}_{11} \mathrm{H}_{12}{ }^{-}$and $\mathrm{MV}^{2+}$ charge transfer complex in the presence of thiophenol $(\mathrm{PhSH})$. This compound is a good electron and hydrogen donor and if $\mathrm{CB}_{11} \mathrm{H}_{12}$ radical is formed, $\mathrm{PhSH}$ should be able to quench the carborane radical by transferring a hydrogen atom. Upon generation of $\mathrm{PhS}^{\bullet}$ thiyl radical, the process should lead to the formation of 1,2-diphenyl disulfide that can be easily detected (Scheme 2).

As expected irradiation with $360 \mathrm{~nm}$ light gives rise to the disappearance of thiophenol and the concomitant formation of 1,2-diphenyl disulfide. A blank control under the same conditions with $\mathrm{MV}^{2+}$ and thiophenol but in the absence of carborane shows that the presence of carborane is responsible for an enhancement of the yield of 1,2-diphenyl disulfide from 25 to $90 \%$.

In summary, unexpectedly in view of the absence of an absorption band in the UV above $200 \mathrm{~nm}, 308 \mathrm{~nm}$ laser flash excitation has allowed detection of the corresponding triplet excited state with a half life of $16.2 \mu \mathrm{s}$. Also unexpectedly in view of its reluctance to undergo electrochemical oxidation, carborane associates with $\mathrm{MV}^{2+}$ forming a charge transfer complex that can be detected by optical spectroscopy and positive ESI-MS. Upon illumination, the charge transfer complex gives rise to a charge separated state, $\mathrm{MV}^{\cdot+}$ radical cation being indefinetely persistent in the absence of oxygen. These results can open new avenues in the chemistry and functionalization of carboranes.

Financial support by the Spanish DGI (CTQ2006-0567) is gratefully acknowledged. F. X. LiX. thanks the Spanish Ministry of Education for a Ramón y Cajal research associate contract.

\section{Notes and references}

1 M. Juhasz, S. Hoffmann, E. Stoyanov, K. C. Kim and C. A. Reed, Angew. Chem., Int. Ed., 2004, 43, 5352-5355.

2 E. S. Stoyanov, K. C. Kim and C. A. Reed, J. Am. Chem. Soc., 2006, 128, 8500-8508.

3 E. S. Stoyanov, S. P. Hoffmann, M. Juhasz and C. A. Reed, J. Am. Chem. Soc., 2006, 128, 3160-3161.

4 C. A. Reed, Chem. Commun., 2005, 1669-1677.

5 S. Korbe, P. J. Schreiber and J. Michl, Chem. Rev., 2006, 106, 5208-5249.

6 P. A. Jelliss, J. Organomet. Chem., 2005, 32, 104-123.

7 C. A. Reed, Chem. Commun., 2005, 1669-1677.

8 N. S. Hosmane, Boron Chemistry at the Beginning of the 21st Century, [Proceedings of the International Conference on the Chemistry of Boron], 11th, Moscow, Russian Federation, July 28-Aug. 1, 2002, 2003, pp. 157 167.

9 R. N. Grimes, Angew. Chem., Int. Ed., 2003, 42, 1198-1200.

10 G. J. Kavarnos and N. J. Turro, Chem. Rev., 1986, 86, 401-449.

11 K. B. Yoon and J. K. Kochi, J. Phys. Chem., 1991, 95, 3780-3790.

12 M. Alvaro, B. Ferrer, V. Fornes and H. Garcia, Chem. Commun., 2001, 2546-2547.

13 M. L. McKee, J. Am. Chem. Soc., 1997, 119, 4220-4223.

14 M. F. Hawthorne, K. Shelly and F. Li, Chem. Commun., 2002, 547-554. 